\title{
DSC, WAXD and SEM studies of biodegradation of poly(L-lactide-glycolide-trimethylene carbonate) shape memory terpolymer
}

\author{
Janusz Fabia · Jarosław Janicki · Tadeusz Graczyk • \\ Piotr Dobrzyński · Janusz Kasperczyk
}

Received: 15 November 2012/ Accepted: 17 May 2013/Published online: 14 June 2013

(C) The Author(s) 2013. This article is published with open access at Springerlink.com

\begin{abstract}
Presented study is a part of structural project devoted to elaborating the basis of manufacturing technology of L-lactide-glycolide-trimethylene carbonate polymer system-a novel full biodegradable and resorbable shapememory polymers. In this paper we took an attempt to describe the transformation of structure of studied shapememory terpolymers under the influence of the process of biodegradation that occurred in time of implantation samples using first of all the differential scanning calorimetry and supplementary-the wide angle X-ray diffraction and scanning electron microscopy methods. After a 5-year-period of ageing the distinct increase of crystallinity of fibres was found.
\end{abstract}

Keywords SMP · Biodegradation - DSC - Structure · Crystallization

\section{Introduction}

Shape-memory polymers (SMPs) are stimuli-responsive materials that can change their shape as a result of an action of various external factors, i.e. changes of: temperature (thermoresponsive SMP), $\mathrm{pH}$ (chemosensitive SMP), light wavelength (photoactive SMP), etc. [1-5]. In the case

J. Fabia · J. Janicki · T. Graczyk ( $\square)$

Institute of Textile Engineering and Polymer Materials, University of Bielsko-Biala, Willowa 2, 43-309 Bielsko-Biała, Poland

e-mail: tgraczyk@ath.bielsko.pl

P. Dobrzyński · J. Kasperczyk

CMPW Center of Polymer and Carbon Materials, Polish

Academy of Sciences, Curie-Skłodowskiej 34, 41-819 Zabrze,

Poland of thermoresponsive SMPs the permanent shape can be formed by a melt processing of them. Then in the so-called 'programming' process at the given temperature range the SMPs need to be deformed to the temporary shape, which is finally fixed by rapid cooling, while the permanent shape is stored in the 'memory'. The permanent shape can be regained by the change of temperature [6-10].

Applications of SMPs are widespread and include sensors, self-repairing bodies, actuators and medical implants [11-17]. SMP can be potentially used for biomedical applications such as bioresorbable implantable materials, as the shape-memory ability can be advantageous in order to minimize surgical impact. Such a solution enables implantation of small-size temporary shape elements which then regains its permanent shape at the body temperature [18].

\section{Experimental}

\section{Materials}

In this paper we present the results of investigations of a special SMP material from the group of biodegradable terpolymers-poly(L-lactide-glycolide-trimethylene carbonate). Earlier the mass fraction of monomers to: LA $67 \%$, GL $11 \%, o$-TMC $22 \%$, respectively, and parameters of polymerization process were optimized. Studied SMP terpolymer, denoted as LP-75, was synthesized by ring-opening polymerization using low-toxicity zirconium(IV) acetylacetonate $\mathrm{Zr}(\mathrm{acan})_{4}$ as an initiator in Center of Polymer and Carbon Materials Polish Academy of Sciences CMPW in Zabrze [18].

The post-reaction form of material was melted (ca. $130{ }^{\circ} \mathrm{C}$ ) and processed into a surgical systems (clips) using the microinjection moulding machine. Investigated materials 
were implanted into bodies of experimental pigs and at established order-reimplanted for structural measurements (Fig. 1).

\section{Measuring methods}

Thermal properties of investigated samples were examined by differential scanning calorimetry (DSC) method. Calorimetric investigations were carried out with a TA Instruments System 5100 equipped with a MDSC Calorimeter 2920 and RCS cooling system. The measurements were performed in the atmosphere of nitrogen (flow $40 \mathrm{~mL} \mathrm{~min}^{-1}$ ) using TA standard aluminium pans. The masses of the examined samples were about $5 \mathrm{mg}$. Heating rate of $10{ }^{\circ} \mathrm{C} \mathrm{min}{ }^{-1}$ was used. The curves were evaluated by means of the Universal V2.6D (TA Instruments) software.

The wide-angle X-ray diffraction measurements (WAXD) were carried out on a Seifert URD6 diffractometer, equipped with ISO-DEBYEFLEX 3003 high voltage generator and a graphite monochromator. The step scanning measurement mode was employed over a $2 \theta$ scattering angle ranging from $5^{\circ}$ to $60^{\circ}$, with a step-size of $0.05^{\circ}$. Temperature time-resolved WAXD measurements were carried out on Kratky camera equipped with Hecus SWAXS optical system. A cooper target-sealed X-ray tube operated at $U=40 \mathrm{kV}$ and $I=30 \mathrm{~mA}$ was used as the radiation source $(\lambda=0.154 \mathrm{~nm})$ during all $\mathrm{X}$-ray investigations.

Scanning electron microscopy (SEM) investigations were carried out by means of a SEM JSM 5500 LV manufactured by JEOL, in the mode of secondary electrons, at the high vacuum. To improve contrast SMP samples viewed under SEM microscope were sputtered with gold.
The observations were performed at accelerating voltage of $10 \mathrm{kV}$. Microphotographs were taken at magnifications from $\times 1,000$ to $\times 10,000$.

\section{Results and discussion}

Discussion of the results of degradation studies in vivo will begin with a comment on the qualitative recognition of changes in the material as a function of implantation time of SMP material in the experimental pigs. The progress of degradation is shown clearly in the SEM micrographs presented in Fig. 2. Even after 4 weeks of implantation, there are clear changes in the microscopic image of the test material. This involves the creation of characteristic manifestations of heterogeneity in its volume as a result of the progressive penetration of the physiological medium (liquid) in biodegradation (Fig. 2b). As indicated, further progress in the process of changing the image of microscopic samples tested SMP exacerbated by the emergence the typical 'craters' of the volume of material (Fig. 2c) until the typical spongy microstructure (Fig. 2d). In this form, the material not only loses any mechanical strength but is also gradually defragmented in terms of macroscopic coherence. After 10 weeks of implantation there is approximately $1 / 10$ of the initial sample mass. The rest of the biodegradable material is mostly reabsorbed by the body.

On the background of presented SEM microscopy studies, the results of calorimetric DSC tests are very interesting, especially in structural terms. As shown by previous research [18], tested terpolymer SMP has a multiblock structure, which governs its shape-memory
Fig. 1 The scheme of obtaining samples for structural investigations

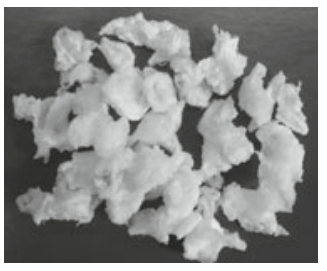

A form of investigated material after polymerization
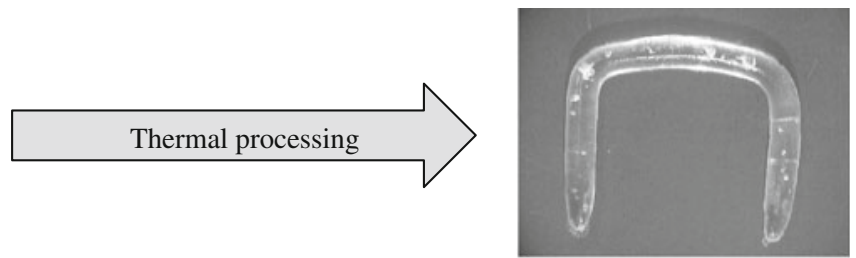

A sample of surgical system with memory of shape (mass of about $65 \mathrm{mg}$ )

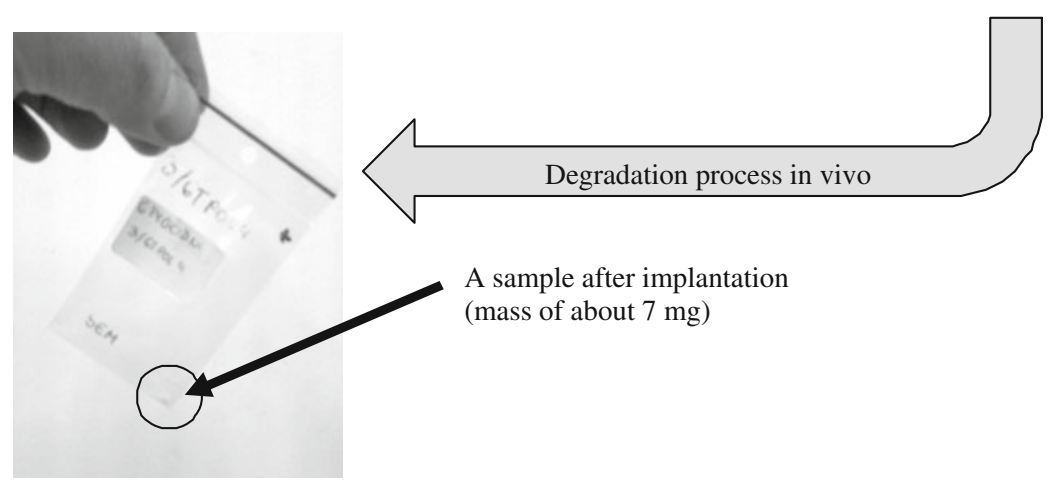


(a)

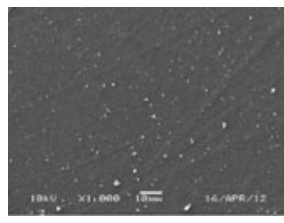

(b)

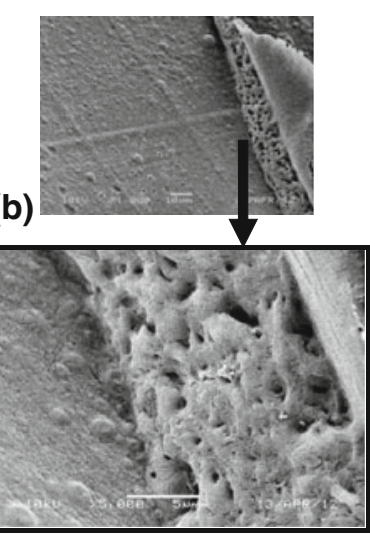

Fig. 2 SEM micrographs of investigated SMP samples during the process of biodegradation in vivo: a material before implantation, b after four implantation-a lot of changes are visible, c after 6 weeks of implantation-a multitude of characteristic 'craters' appeared in

properties. However, in the 'starting conditions', i.e. immediately after processing from the reaction in the form of a surgical stent, there are no 'signs' of the crystalline structure. The DSC curve (Fig. 3) obtained in heating mode (range $0-200{ }^{\circ} \mathrm{C}$ ) shows the glass transition at $38{ }^{\circ} \mathrm{C}$, which is accompanied by a characteristic enthalpy relaxation peak $\left(43^{\circ} \mathrm{C}\right)$ with high intensity but does not show any endothermic melting effects (curve 'a' on Fig. 3). This is unlike the calorimetric results for the samples treated with SMP biodegradation processes in vivo. The shape of DSC curve in this case is quite different (line ' $b$ ' on Fig. 3).

Comparison of DSC curves obtained for the samples after the implantation process is shown on Fig. 4. The values of characteristic temperatures and enthalpies changes corresponding to the transitions reflected on the curves are shown in Table 1 . On the curves at temperatures above $70{ }^{\circ} \mathrm{C}$ a very clear melting peak appears, which indicates that in the (c)
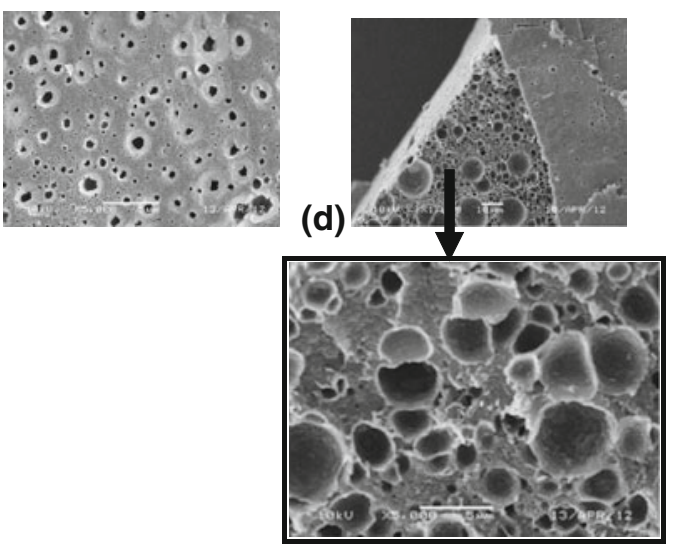

the volume of a sample, $\mathbf{d}$ after 10 weeks of implantation-total loss of coherence of a sample, different characters of core and surface, spongy character of a black arrow marked fragment of a sample

process of biodegradation, there simultaneously occurs a structure ordering process. Crystallites are created in this process that melt when heated above $70^{\circ} \mathrm{C}$ during DSC measurement. This property of the material disappears after 10 weeks of implantation, and may be associated with arrangement appearing within TMC blocks, as seen by WAXD results qualitatively discussed in a further part of this paper.

With further heating of the samples, as seen in the curves presented in Fig. 4, an exothermic recrystallization effect appears (curves a-c). This is formed in the recrystallization process arrangement and is destroyed in the melting process. The melting process shown on the DSC curves presented is in the form of a characteristic endothermic peak whose position is monotonically shifted to lower temperatures, while its intensity increases with increasing implantation time-the biodegradation of the test material (Table 1).
Fig. 3 DSC curves registered during the heating for investigated SMP material before (curve a) and after degradation process (curve b)

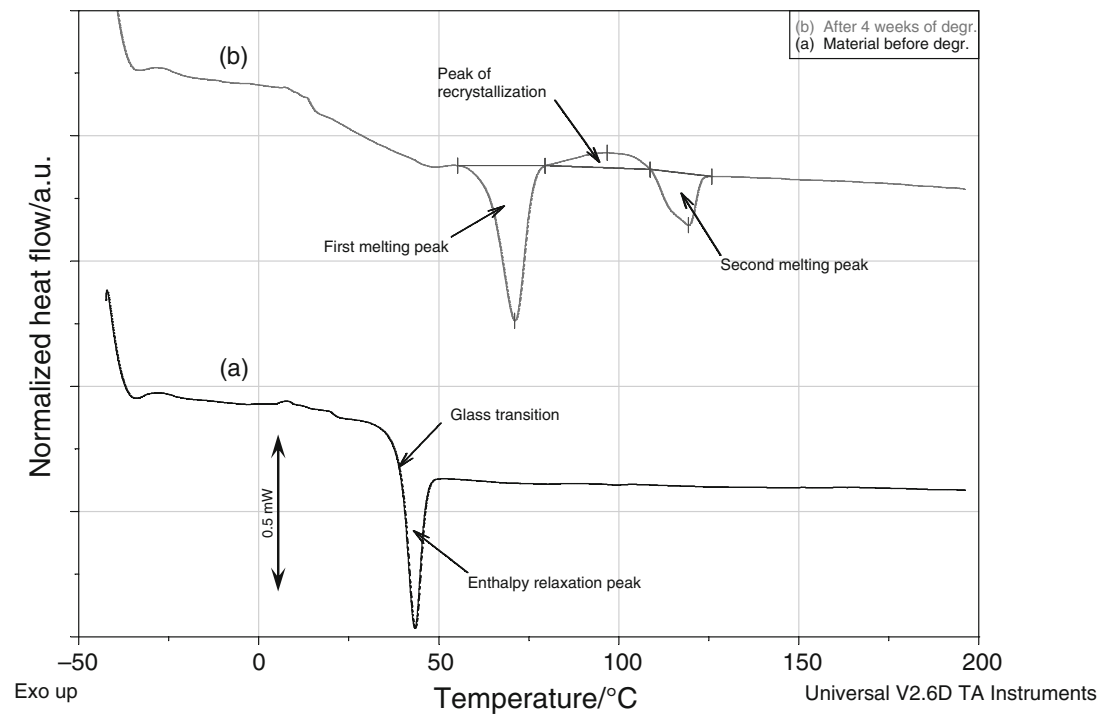


Fig. 4 DSC curves for material reimplanted from the pigs bodies after: (a) 4 weeks, (b) 6 weeks, (c) 8 weeks and (d) 10 weeks of the degradation process in vivo

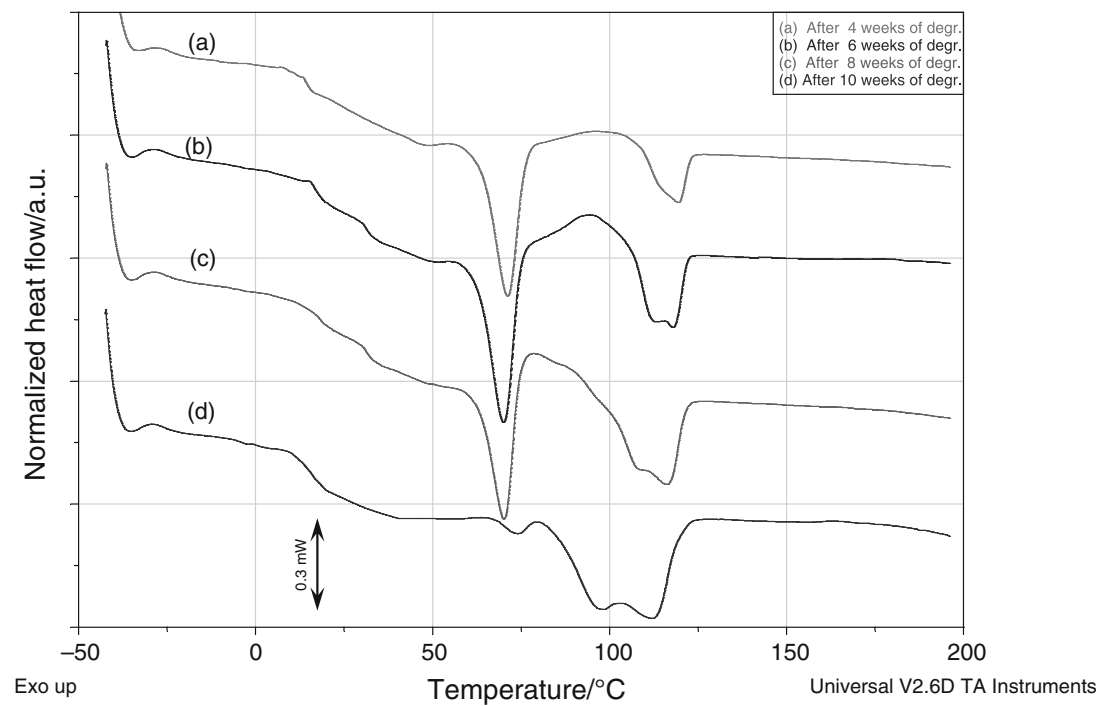

Table 1 Values of: temperatures of melting $T_{\mathrm{m} 1}, T_{\mathrm{m} 2}$, enthalpies of melting $\Delta H_{\mathrm{m} 1}, \Delta H_{\mathrm{m} 2}$ and recrystallization $\Delta H_{\mathrm{r}}$, respectively, evaluated on the basis of DSC curves (Fig. 2) for samples of SMP materials reimplanted from the bodies of pigs after different periods of biodegradation in vivo

\begin{tabular}{llllll}
\hline $\begin{array}{l}\text { Implantation } \\
\text { periods (weeks) }\end{array}$ & $\begin{array}{l}\text { Temperature of melting } \\
(1 \mathrm{st} \text { melting peak) } \\
T_{\mathrm{m} 1} /{ }^{\circ} \mathrm{C}\end{array}$ & $\begin{array}{l}\text { Enthalpy of melting } \\
(1 \mathrm{st} \mathrm{melting} \mathrm{peak)} \\
\Delta H_{\mathrm{m} 1} / \mathrm{J} \mathrm{g}^{-1}\end{array}$ & $\begin{array}{l}\text { Enthalpy of } \\
\text { recrystallization } \\
\Delta H_{\mathrm{r}} / \mathrm{J} \mathrm{g}^{-1}\end{array}$ & $\begin{array}{l}\text { Temperature of melting } \\
(2 \mathrm{nd} \text { melting peak) } \\
T_{\mathrm{m} 2} /{ }^{\circ} \mathrm{C}\end{array}$ & $\begin{array}{l}\text { Enthalpy of melting } \\
\text { (2nd melting peak) } \\
\Delta H_{\mathrm{m} 2} / \mathrm{J} \mathrm{g}\end{array}$ \\
\hline 4 & 71.1 & 12.0 & 2.7 & 119.4 & 4.3 \\
6 & 70.1 & 12.9 & 5.1 & $110.5 / 117.8$ & 7.4 \\
8 & 70.2 & 8.3 & 5.5 & $108.6 / 116.2$ & 12.7 \\
10 & 74.0 & 0.8 & - & $98.4 / 112.1$ & 24.0 \\
\hline
\end{tabular}

The discussed melting peak exhibits characteristic splitting that is likely to be the effect of crystallographic polymorphism within the polylactide crystalline phase. The temperature range of the occurrence of this peak indicates that the effect of this change is reflected in the melting of the crystallites within lactide blocks. This inference is confirmed by diffraction WAXD (Fig. 5) studies carried out in parallel.

Fig. 5 WAXD curves of SMP: matrix and samples after 4, 6, 8 and 10 weeks of implantation, respectively
On the diffraction patterns obtained for samples of SMP materials measured after the different periods of implantation (Fig. 5) besides the diffraction peaks characteristic for the crystalline phase of poly(L-lactide) $-2 \theta=19.31^{\circ}$ and $22.11^{\circ}$, respectively, the arrangement of diffraction maximums which we assigned to molecular crystals inside TMC blocks unequivocally are visible (Fig. 6).

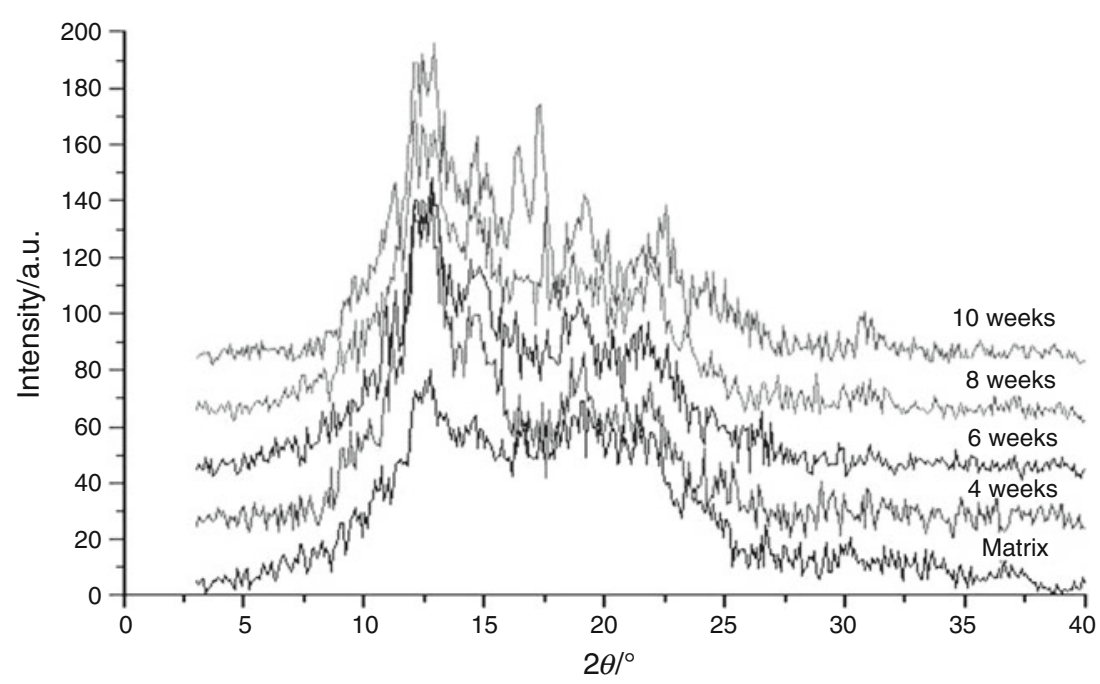




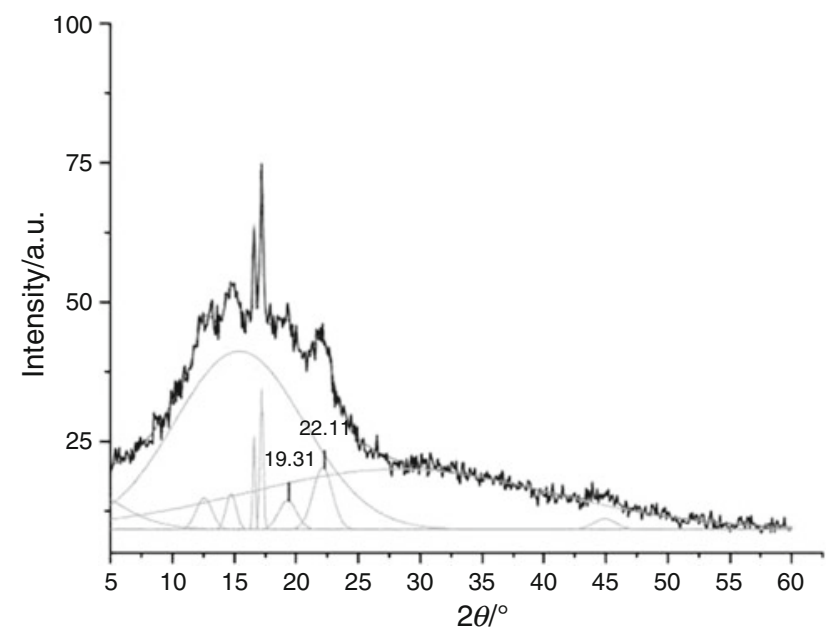

Fig. 6 Exemplary WAXD curve (black line) for the biodegraded SMP material resolved for individual diffraction peaks (grey lines) [19-21]. The diffraction maximums characteristic for crystalline form of poly(L-lactide) are marked with labels

\section{Conclusions}

On the basis of the performed analysis (calorimetric DSC studies, supplementary SEM microscopy and WAXD diffraction), it is clear that studied poly(L-lactide-glycolideTMC) shape-memory terpolymer exhibits two-phase supermolecular structure i.e. an amorphous and a crystalline phase.

In the biodegradation process during the implantation of the tested SMP terpolymer, there occurs a fundamental and characteristic change in the appearance of crystalline phase in the structure with increasing implantation time.

This appearance of crystalline structure can be quantitatively evaluated by the increase of the enthalpy of melting from above 4 to $24 \mathrm{~J} \mathrm{~g}^{-1}$ (last column on Table 1). The explanation of this fact refers to the increase in mobility of the macromolecules in the formation of crystallites as a result of shortening their length-that is reduction of the molecular mass as a result of biodegradation occurs in vivo.

Acknowledgments Presented investigations have been realized as an integral part of Project 'MEMSTENT' which is financed in the framework of 'Innovative Economy' Programme, Contract No.: UDA-POIG.01.03.01-00-123/08.

Open Access This article is distributed under the terms of the Creative Commons Attribution License which permits any use, distribution, and reproduction in any medium, provided the original author(s) and the source are credited.

\section{References}

1. Lendlein A, Kelch S. Shape-memory polymers. Angew Chem Int Ed. 2002;41:2035-57.

2. Hengfeng L, Kaiyuan T, Zeming H, Guowen H. Thermal characterization of a series of poly(vinylidenefluoride-chlorotrifluoroethylene-trifluoroethylene) terpolymer films. J Therm Anal Calorim. 2011;105:357-64.

3. Herbert JM, Glass AM, Wang TT. The application of ferroelectric polymers. New York: Chapman and Hall; 1988.

4. Buckley GS, Roland CM, Casalini R, Petchsuk A, Chung TC. Electrostrictive properties of poly(vinylidenefluoride-trifluoroethylene-chlorotrifluoroethylene). Chem Mater. 2002;14(6):2590-3.

5. Wang Z, Zhang Z, Chung TCM. High dielectric VDF/TrFE/ CTFE terpolymers prepared by hydrogenation of VDF/CTFE copolymers: synthesis and characterization. Macromolecules. 2006;39(13):4268-71.

6. Kim BK, Lee SY, Xu M. Polyurethane having shape memory effects. Polymer. 1996;37:5781-93.

7. Lendlein A, Schmidt AM, Langer R. AB-polymer networks based on oligo(epsilon-caprolactone) segments showing shape-memory properties. Proc Natl Acad Sci USA. 2001;98:842-7.

8. Ping P, Wang W, Chen X, Jing X. Poly(epsilon-caprolactone) polyurethane and its shape-memory property. Biomacromolecules. 2005;6:587-92.

9. Wang W, Ping P, Chen X, Jing X. Polylactide-based polyurethane and its shape-memory behavior. Eur Polym J. 2006;42:1240-9.

10. Xu J, Shi W, Pang W. Synthesis and shape memory effects of Si-O-Si cross-linked hybrid polyurethanes. Polymer. 2006;47:457-65.

11. El Feninat F, Laroche G, Fiset M, Mantovani D. Shape memory materials: biomedical applications. Adv Eng Mater. 2002;4:91-104.

12. Kaway T, Matsuda T. Plastic Molded Articles with shape memory properties. US Patent 4950258. 1990.

13. Lendlein A, Langer R. Biodegradable, elastic shape-memory polymers for potential biomedical applications. Science. 2002; 296:1673-6.

14. Lendlein A, Knischka R, Kratz K. Shape memory thermoplastics and polymer networks for tissue engineering. US Patent 2004110285. 2004.

15. Shikinami Y. Shape-memory, biodegradable, absorbable material. US Patent 6281262. 2001.

16. Venkatraman SS, Tan LP, Joso JFD, Boey YCF, Wang X. Biodegradable stents with elastic memory. Biomaterials. 2006;27: 1573-8.

17. Yakacki CM, Shandas R, Lanning C, Rech B, Eckstein A, Gall K. Unconstrained recovery characterization of shape-memory polymer networks for cardiovascular applications. Biomaterials. 2007;28:2255-63.

18. Zini E, Scandola M, Dobrzyński P, Kasperczyk J, Bero M. Shape memory behavior of novel (L-lactide-glycolide-trimethylene carbonate) terpolymers. Biomacromolecules. 2007;8:3661-7.

19. Rabiej M. Wyznaczanie stopnia krystaliczności polimerów semikrystalicznych przy pomocy programu komputerowego "OptiFit". Polimery. 2002;47:423-7.

20. Rabiej M. Zastosowanie optymalizacji wielokryterialnej do wyznaczania stopnia krystaliczności polimerów semikrystalicznych. Polimery. 2003;48:288-95.

21. Rabiej M. Application of the genetic algorithms and multiobjective optimization to the resolution of X-ray diffraction curves of semicrystalline polymers. Fibres Text East Eur. 2003; 11(5):83-5. 